\title{
A Review on Salivary Proteomics for Oral Cancer Screening
}

\section{Qian $\mathrm{Li}^{1,2}$, Xiangying Ouyang ${ }^{2}$, Jiao Chen ${ }^{1}$, Ping Zhang ${ }^{1 \#}$ and Yun Feng ${ }^{1 \#}$}

1State Key Laboratory of Oral Diseases, National Clinical Research Center for Oral Diseases, West China Hospital of Stomatology, Sichuan University, Chengdu, China.

2Department of Periodontology, School and Hospital of Stomatology, Peking University, Beijing, China.

\# Corresponding authors:

pingzhang68@hotmail.com, 953463551@qq.com

DOI: https://doi.org/10.21775/cimb.037.047

\begin{abstract}
Oral cancer has emerged as a global health problem due to its relatively high incidence and mortality. Human saliva as a diagnostic fluid can offer an easy, inexpensive, safe and non-invasive approach for disease detection. Direct contact between saliva and oral cancer lesions make detection of salivary biomarkers for oral cancer especially attractive. Proteins are important molecules involved in pathological processes of oral cancer growth, apoptosis and metastasis. Proteins such as hormones, antibodies, enzymes and cytokines in saliva secreted by oral cancer cells or by host cells not only provide comprehensive pathological information of oral cancer but also are considered potential targets for non-invasive screening of oral cancer. This article provides a review of potential salivary proteomic biomarkers in oral cancer screening.
\end{abstract}

\section{Introduction}

Oral cancer, over $90 \%$ of which is oral squamous cell carcinoma (OSCC), has emerged as a global health problem due to its relatively high incidence and mortality(Siegel et al., 2018). The 5-year survival rate of advanced (stages III and IV) oral cancer is about $20 \%$, although surgery and radiochemotherapy have made great progresses for treatments of oral cancer (Van, 2013). Early screening and detection are still the most effective strategies in reducing morbidity of oral cancer. Salivary biomarkers could be excellent and convenient tools for achieving public screening of oral cancer at early stage. And it is recommended that oral cancer suspected by early screening should be definitely diagnosed by tissue biopsy.

The whole saliva contains a library of proteins like hormones, antibodies, enzymes and cytokines which reflect health and disease states. Oral cancer-related proteins released by oral cancer cells or by host immune cells can enter the saliva directly and provide relative information of oral cancer(Loo et al., 2010; Kaczor-Urbanowicz et al., 2016).More than 2000 proteins and peptides related with oral cancer and systemic diseases in saliva have been discovered(Wong, 2012). Comprehensive analysis of salivary proteome can help us to deepen the understanding of oral cancer and to seek potential biomarkers for early non-invasive screening of oral cancer(Zhang et al., 2013; Cheng et al., 2014).

\section{Saliva: an alternative diagnostic fluid}

Saliva has long been considered a potential alternative to blood serum and urine to provide a mirror of the body's health. It is a mixture of secretions mainly from three major glands (submandibular, sublingual and parotid) and minor salivary glands. Meanwhile, gingival crevicular fluid (GCF), microorganisms and their products, food debris, and desquamated epithelial cells are also important components of saliva(Chaubron, 2015). In some exceptional cases, saliva even contains expectorated bronchial secretions, serum and blood derivatives from oral wounds (Malathi et al., 2014). Analysis of saliva offers several benefits including non-invasive and stress-free sample collection, easy storage and transportation, patients cooperation in providing samples, cost effectiveness, and minimal risk of infection, compared to traditional blood or tissue-based biochemical analysis(Singh and Prasad G., 2014; Nunes et al., 2015a). There is a growing interest in saliva for the extensive 
biological information contained in it (Panta and Wong, 2019), and modern conception of "salivaomics" is subsequently put forward which includes six diagnostic alphabets: salivary genomics, transcriptomics, proteomics, metabolomics, microbiomics and microRNA (miRNA) (Kaczor-Urbanowicz et al., 2017).

\section{Salivary proteomics}

\section{Composition of the salivary proteomics}

It is noteworthy that there is a poor correlation between salivary transcriptomics and salivary proteomics since proteins has no strict linear relationship with genomes(or mRNA) : modifications of proteins like post-translational modifications (PTM) endow proteins with complex structural and functional features; Complex network of interactions is found among salivary proteins (Pandey and Mann, 2000).
Bandhakavi et al(Bandhakavi et al., 2009) has detected 2340 proteins in saliva and they presented the largest salivary proteomic dataset to date by using an analysis platform coupled hexapeptide library for dynamic range compression with threedimensional peptide fractionation. Saliva contains about $30 \%$ of the proteins found in blood, but some salivary proteins with specific roles are only produced in oral cavity (Perezcornejo et al., 2012). There are six major families of proteins involved in salivary proteomics: proline-rich proteins (PRPs) including acidic PRP(aPRP), basic PRP (bPRP) and glycosylated PRP(gPRP), a-amylases, mucins, salivary (S-type) cystatins, histatins and statherin (Figure 1) (Castagnola et al., 2012a; Schulz et al., 2013a). Although some of their concentrations are 10-15 times lower than protein concentrations in plasma, the advancements in analytical highthroughput technology has greatly increased the detection sensitivity and specificity of proteomic biomarkers in saliva( Sivadasan et al., 2015; Liang et al., 2016; Sun et al., 2018).

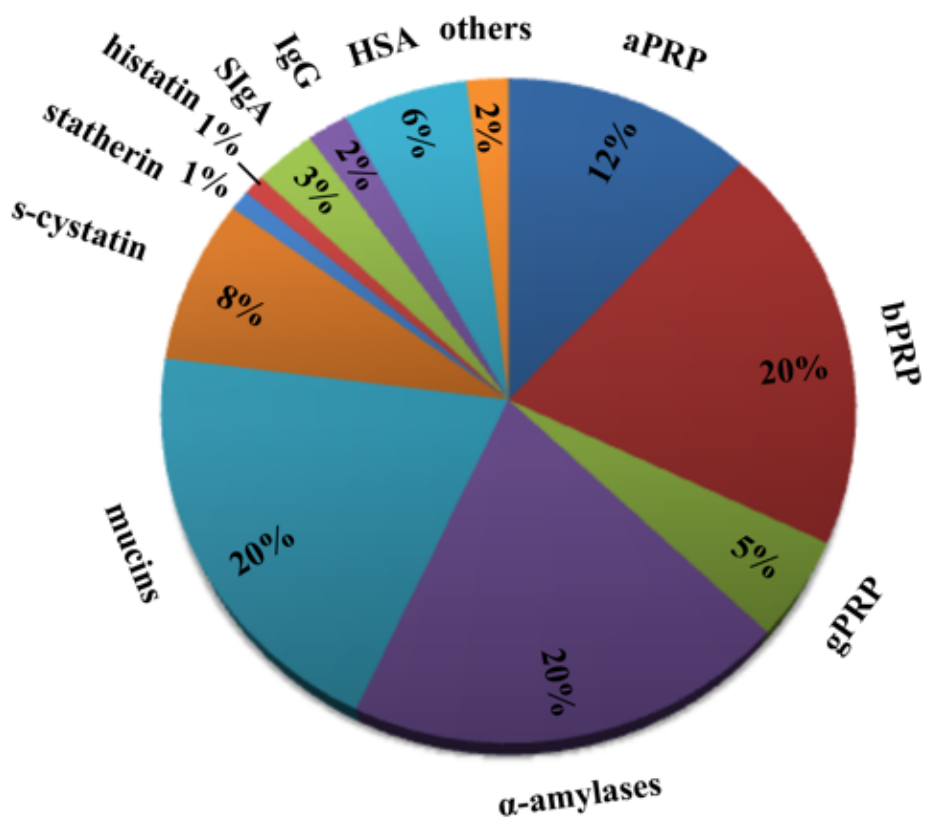

Figure 1. Major proteins in human saliva (\%). 
Methods of salivary proteome analysis

Considering proteomes in saliva are vulnerable to outside factors, saliva shall be submitted to preanalytical treatments as follows: Collected saliva must be refrigerated at $4{ }^{\circ} \mathrm{C}$ and then be operated in a low temperature to avoid bacterial contamination within 3 to 6 hours (Kawas et al., 2012; Nunes et al., $2015 b)$. Besides, addition of sodium azide in saliva is recommended to inhibit bacterial growth, but it may cause adverse interference in immunoassays with horseradish peroxidase(Nunes et al., 2011). It is also useful to apply protease inhibitors and stabilizers like EDTA, aprotinin, leupeptin and thimerosal to avoid protein degradation(Haywood et al., 2011).

Analytical techniques for salivary proteomics are roughly classified into top-down and bottom-up strategies (Figure 2) (Castagnola et al., 2012; Martelli et al., 2014; Sannam et al., 2016). Top-down proteomics focuses on analysis of the intact naturally occurring proteome while bottom-up proteomics is used to analyze salivary proteins which have been digested. Two-dimensional gel electrophoresis (2DGE), a top-down platform, is the most basic technology allowing separation of complex protein mixtures more than 5000 proteins (Karsani et al., 2014; Santucci et al., 2015). However, this method has inevitable shortcomings: firstly, small proteins or peptides with very acidic or basic isoelectric point ( $\mathrm{pl}$ ) may migrate outside its analysis ranges(Rabilloud, 2015); secondly, highly abundant proteins can obscure the less abundant ones by this method; finally, this method suffers from many variabilities such as gel preparation, unusual migration and staining of protein isoforms.

Mass spectrometry (MS) with fast speed and high sensitivity allows us to examine salivary proteomes in level of expressions as well as posttranslational modifications. This method is usually combined with Surface-enhanced laser desorption ionization (SELDI), matrix-assisted laser desorption ionization (MALDI) or time-of-flight (TOF) to measure intact proteins or peptides. SELDI-TOF-MS plays an important role in sample purification, desorption/

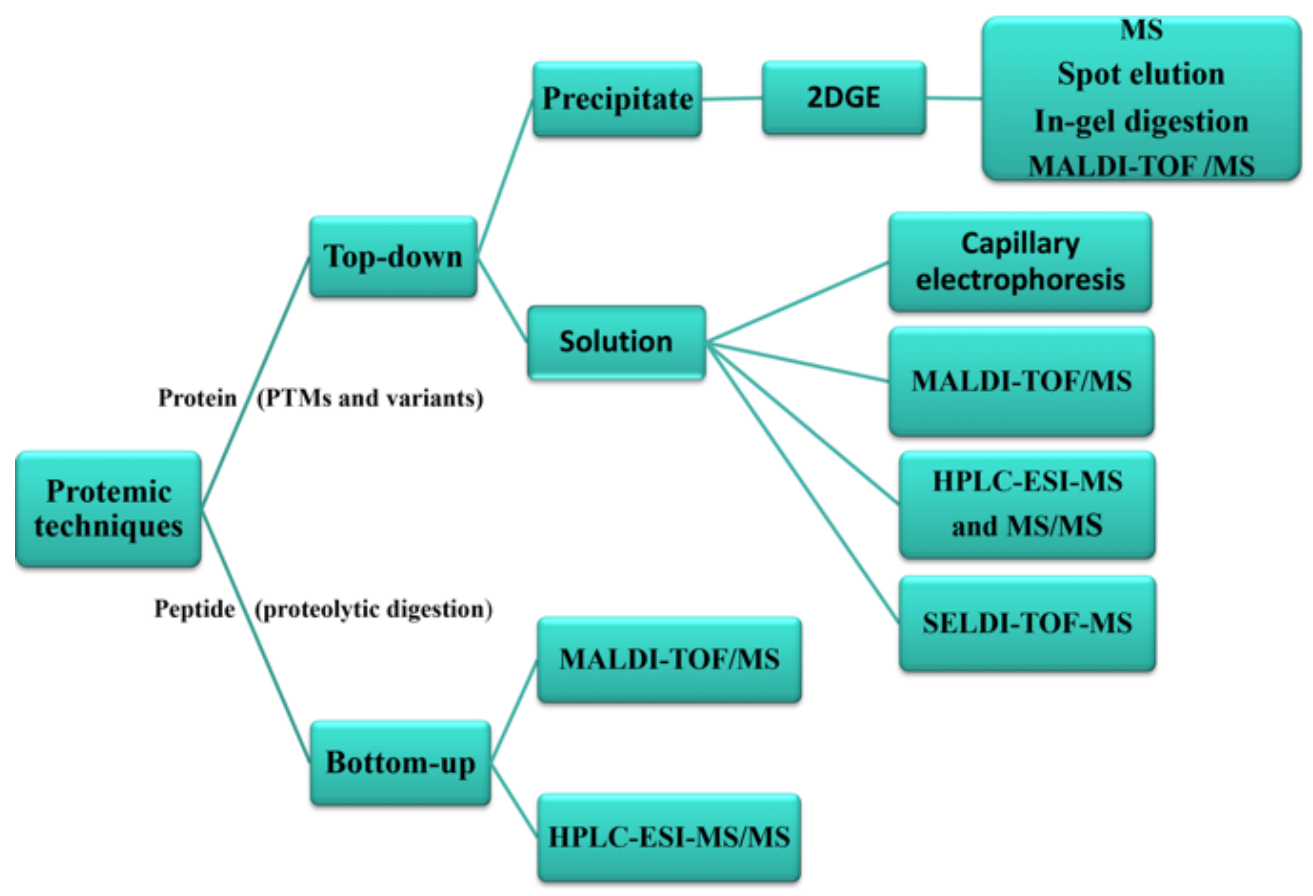

Figure 2. Integrated top-down and bottom-up proteomics approaches. 
ionization and protein separation in Protein Chip (AlTarawneh et al., 2011; Ardito et al., 2016). By comparison, MALDI-TOF-MS with higher sensitivity and simplicity can be used for initial profiling prior to further identification by HPLC-MS (Al-Tarawneh et al., 2011). Chemical labeling techniques including isotope-coded affinity tags(ICAT), isotope tags for relative and absolute quantification (iTRAQ), absolute quantification of proteins using internal standards (AQUA) and stable isotope labeling by amino acids in cell culture (SILAC) are also widely used to observe quantitative alterations of salivary proteome in changeable stages(Castagnola et al., 2012a; Sannam et al., 2016).

\section{Salivary proteomics for oral cancer}

\section{Saliva proteomic biomarkers for oral cancer}

Recently, Chen et al(Chen et al., 2017) found 25 out of 56 salivary proteins were significantly different between OSCC patients and controls (fold change > $5, p<0.05, n=119$ ) by selected/multiple reaction monitoring (SRM/MRM). More importantly, they suggested to combine biomarkers Complement factor $\mathrm{H}(\mathrm{CFAH}), \mathrm{C}$-reactive protein(CRP) with fibronectin(FINC) (>10 foldchange, $P<0.05$, and area under the curve $>0.8$ ) to early screen oral cancer. Similarity, Krapfenbauer et al(Krapfenbauer, 2014) identified 25 proteins specific for OSCC and they recommended them as potential biomarkers for oral cancer. Moreover, out of these 25 proteins, 12 have never been reported: proteinsgalectin-7, cofilin, CRP precursor, creatine kinase, m-chain, fatty acid binding protein, keratin type II, myosin light chain 2 and 3 , nucleoside diphosphate kinase $A$, phosphoglycerate mutase 1 , plakoglobin, and retinoic acid binding protein II. Gallo et al (Gallo et al., 2016) also analyzed data of saliva from OSCC patients and healthy controls(CTRL), in order to validate the salivary proteomic signatures of OSCC. Their Mann-Whitney test showed 22 peaks were significant between controls and OSCC; 15 and 16 significant peaks were identified comparing CTRL to $\mathrm{N}$ - and $\mathrm{N}+$ respectively $(\mathrm{N}+$ and $\mathrm{N}$ - denoting the presence or absence of lymph node metastasis respectively); 6 different peaks were identified in $\mathrm{N}$ to $\mathrm{N}+$ samples.

It has long been believed that there is a strong link between chronic inflammation and oral cancer where cute-phase response proteins(APPs) play different roles(Marx). APPs family members Haptoglobin $\beta($ HAP $\beta), \quad \alpha$-antitrypsin(AAT $\alpha)$, complement-C3(C3), hemopexin(HPX), serotransferrin, transthyretin(TTR) and fibrinogen $\beta(F I B \beta)$ were detected in saliva of patients with OSCC. The authors furtherly demonstrated that the increased levels of HAP $\beta$, AAT $\alpha$, C3, HPX, TF, TTR, FIB $\beta$ and $A B G$ were potential biomarkers for the early detection of OSCC(Jessie et al., 2013). To the best of our knowledge, this is the first report of enhanced expression of AAT,HAP $\beta, C 3, H P X, T T R$ and $A B G$ in the saliva of OSCC patients. Yu et al (Yu et al., 2016) assembled an inflammatory protein panel which consists of matrix metalloproteinase-1(MMP1), kininogen1(KNG1), annexin a2(ANXA2) and heat shock protein A5 (HSPA5) to early screen OSCC. In addition to MMP-1 mentioned in their study, MMP family members like MMP-2, $-3,-9,-10,-12$, and -13 have also been demonstrated to be related with oral cancer (Han et al., 2014; Agha-Hosseini and Mirzaii-Dizgah, 2015; Ghallab and Shaker, 2016). There was a new discovery that polymorphisms in MMP genes contribute to OSCC, which expand our knowledge of the roles of MMPs in the process of oral cancer (Pereira et al., 2012).

Besides biomarkers above discovered by highthroughput methods, there are some potential proteomic biomarkers newly recommended by traditional methods. Resistin(RETN) is a cysteinerich adipose-derived peptide hormone which also known as adipose tissue-specific secretory factor (ADSF) (Kao and Tang, 2014). It was initially shown to function as endocrine hormone and was later demonstrated to participate in type II diabetes mellitus, inflammation and heart disease. Increasing evidences demonstrated RETN was highly correlated with the late-stage OSCC and lymphnode metastasis. This result suggested RETN is a potential salivary biomarker for the early diagnosis and prognosis estimation of OSCC (Wu et al., 2015). In addition, reactive oxygen species (ROS) have been proved to be implicated in the genesis and promotion of oral cancer, and salivary albumin as part of compensatory antioxidant defense system was implicated in a significant increase in oral precancer and oral cancer cases. This result indicated that albumin may play a vital role in the diagnosis and prognosis of premalignant and malignant oral disease by virtue of its antioxidation role in counteracting oxidative stress(Metgud and Patel, 2014). Immunogenic proteins have also attracted considerable attention in the early detection of oral cancer. More recently, four promising proteins known as human pancreatic alpha-amylase(HPA), human salivary amylase (sAA), keratin-10 (K-10) and human serum albumin (GA-HSA) have been implicated as salivary 
biomarkers for OSCC, although further validations are required (Mu et al., 2014).

We summarized the representative salivary proteomic biomarkers for oral cancer (Table 1). These results demonstrated that salivary proteins exhibit significant characters in OSCC patients. Moreover, some of them may be related to lymph node metastasis and ultimately contribute to the early diagnosis and prognosis estimation of oral cancer.

\section{Challenges in salivary proteomic research}

Although salivary proteomic analysis holds great promise, there are still some barriers to transfer this technology from the laboratory to clinical practice(Kaur et al., 2018). Complicity of proteome caused by PTMs is one of the most troublesome

Table 1. Potential salivary biomarkers for oral cancer detection.

\begin{tabular}{|c|c|}
\hline Protein name & Representative reference \\
\hline$\alpha$ - amylase & $\begin{array}{l}\text { Quantitative proteomic analysis reveals decreased salivary amylase in } \\
\text { oral cancer(Rhodus, Jamison, STONE, \& Griffin, 2012). }\end{array}$ \\
\hline Albumin & $\begin{array}{l}\text { Serum and salivary levels of albumin as diagnostic tools for oral pre- } \\
\text { malignancy and oral malignancy(Metgud \& Patel, 2014). }\end{array}$ \\
\hline IL-1 $\beta$ & $\begin{array}{l}\text { Interleukin-1 beta in unstimulated whole saliva is a potential biomarker } \\
\text { for oral squamous cell carcinoma(Kamatani et al., 2013). }\end{array}$ \\
\hline $\begin{array}{l}\text { IL-6 } \\
\text { IL-8 } \\
\text { TNF- } \alpha\end{array}$ & $\begin{array}{l}\text { Salivary IL-8, IL-6 and TNF- } \alpha \text { as Potential Diagnostic Biomarkers for } \\
\text { Oral Cancer(Sahibzada et al., 2017). }\end{array}$ \\
\hline Defensin-1 & $\begin{array}{l}\text { Defensin, a peptide detected in the saliva of patients with oral cancer } \\
\text { patients(Mizukawa, 2011). }\end{array}$ \\
\hline $\begin{array}{l}\text { CD44 } \\
\text { CD59 }\end{array}$ & $\begin{array}{l}\text { Salivary protein and solCD44 levels as a potential screening tool for } \\
\text { early detection of head and neck squamous cell carcinoma.(Franzmann } \\
\text { et al., 2012) } \\
\text { Development of salivary markers for the early detection of oral } \\
\text { squamous cell carcinoma(Romero, Thong, Poon, \& Soo, 2013). }\end{array}$ \\
\hline $\begin{array}{l}\text { Fibronectin(FINC) } \\
\text { C-Reactive protein (CRP) } \\
\text { Complement factor H(CFAH) }\end{array}$ & $\begin{array}{l}\text { Development of a multiplexed LC-MRM/MS method for evaluation of } \\
\text { salivary proteins as oral cancer biomarkers(Chen et al., 2017). }\end{array}$ \\
\hline $\begin{array}{l}\text { Complement factor B(CFB) } \\
\text { Complement C4-B(C4B) Alpha-1- } \\
\text { antitrypsin(SERPIA) } \\
\text { Leucine-richalpha-2- } \\
\text { glycoprotein1 ( LRG1) }\end{array}$ & $\begin{array}{l}\text { A targeted proteomic strategy for the measurement of oral cancer } \\
\text { candidate biomarkers in human saliva(Kawahara et al., 2016). }\end{array}$ \\
\hline Resistin( RETN) & $\begin{array}{l}\text { Saliva proteome profiling reveals potential salivary biomarkers for } \\
\text { detection of oral cavity squamous cell carcinoma(Wu et al., 2015). }\end{array}$ \\
\hline $\begin{array}{l}\text { Haptoglobin(HAP } \beta) \\
\text { Hemopexin(HPX) } \\
\text { Serotransferrin(TF) } \\
\text { Transthyretin(TTR) } \\
\text { Fibrinogen } \beta(F I B \beta) \\
\alpha-1 B \text { glycoprotein(ABG) }\end{array}$ & $\begin{array}{l}\text { Aberrant proteins in the saliva of patients with oral squamous cell } \\
\text { carcinoma(Jessie et al., 2013). }\end{array}$ \\
\hline $\begin{array}{l}\text { Actins } \\
\text { Zinc finger protein 28( HZF28) } \\
\text { Regulator G-protein } 3 \\
\text { Indoleamine2,3-dioxygenase (IDO) } \\
\text { Oral-facial-digital syndrome type } 1 \\
\text { (OFD1) } \\
\text { Centrosomal protein290(CEP290) } \\
\text { Annexin } 1\end{array}$ & $\begin{array}{l}\text { Mass Spectrometry-Based Salivary Proteomicsfor the Discovery of } \\
\text { Head and Neck Squamous Cell Carcinoma(Jarai et al., 2012). }\end{array}$ \\
\hline
\end{tabular}


Annexin a2(ANXA2)

Kininogen1(KNG1)

Heat shock protein(HSPA5)

MMP-1

MMP-2

MMP-9

MMP-10

MMP-12

MMP-13
MMP-3

Saliva protein biomarkers to detect oral squamous cell carcinoma in a high-risk population in Taiwan(Yu et al., 2016).

Association between matrix metalloproteinase 1 (-1607 1G/2G) polymorphism and cancer risk: a meta-analysis including 19706 subjects(G. Han et al., 2014).

Serum and Saliva MMP-3 in Patients with OLP and Oral SCC.

(Aghahosseini et al., 2015)

Serum and salivary levels of chemerin and MMP-9 in oral squamous cell carcinoma and oral premalignant lesions(Ghallab \& Shaker, 2016).

Tumor and salivary matrix metalloproteinase levels are strong diagnostic markers of oral squamous cell carcinoma(Stottmiller et al., 2011).

Serum and saliva collagenase-3 (MMP-13) in patients with oral lichen planus and oral squamous cell carcinoma(Agha-Hosseini \& MirzaiiDizgah, 2015).

Mac-2 binding protein(M2BP)

Myeloidrelatedprotein14(MRP14)

Profilin

Catalase

Salivary proteomics for oral cancer biomarker discovery(Hu et al., 2008).

Endothelin-1

Ga Module Complexed with Human S Detection of host-specific immunogenic proteins in the saliva of patients erum Albumin (GA-HSA)

Keratin-10 (K-10)

Keratin-2(K-2)

Galectin-7

Cofilin

CRP precursor

Creatine kinase m-chain

Fatty acid binding protein(FABP)

Myosin light chain 2, 3(MLC-2,3)

Nucleoside diphosphate kinase

(NDKA)

Phosphoglycerate mutase 1

(PGAM1)

Plakoglobulin (PG)

Retinoic acid binding protein 2

(CRABP-2)

Alpha-fetoprotein (AFP)

Carcinoembryonic antigen (CEA)

\section{CA125}

TissuePolypeptide-specific antigen (TPA)

Basic fibroblast growth factor (FGF2)

\section{Enolase-1}

Enzyme nicotinamide $\mathrm{N}$ methyltransferase

(NNMT)

Lactate Dehydragenase (LDH)
Identification of tumour-related proteins as potential screening markers by proteome analysis_-protein profiles of human saliva as a predictive and prognostic tool(K Krapfenbauer, Drucker, \& Thurnher, 2014).
Expression and clinical significance of AFP and CEA in serum and saliva of patients with oral squamous cell carcinoma(Xu \& Department, 2016).

Saliva CA125 and TPS levels in patients with oral squamous cell carcinoma(Geng et al., 2013).

The evaluation of basic fibroblast growth factor and fibroblastic growth factor receptor 1 levels in saliva and serum of patients with salivary gland tumor(Huang, Li, Li, Jin, \& Ma, 2012).

A screening test for oral cancer using saliva samples: Proteomic analysis of biomarkers in whole saliva(Katakura et al., 2015).

Analysis of tissue and salivary nicotinamide $\mathrm{N}$-methyltransferase in oral squamous cell carcinoma: basis for the development of a noninvasive diagnostic test for early-stage disease(Sartini et al., 2012).

A study of Salivary Lactate Dehydragenase (LDH) level in normal individuals and the Oral Cancer Patients(Nandakumar. \& Savitha, 2015).

Other proteins: P53; Ki67; CA15-3; Cyclic D1; Cyfra 21.1; S100A2,7,9; STAT3; Statherin; Stratifin; Transferrin; Kallikerin-7; Glycolytic enzyme; IgG; Telomerase; Thioredoxin ; Cystatin A; Truncated cystatin SA-I; Rostate specific antigen (PSA); Adenosine ; Transforming growth factor (TGF-1); Antioxidant like-1 (AOP-1); Deaminase (ADA); Serpin B3(SCCA1); 8-oxoquanine DNA glycosylase (OGG1); 
impediments. PTMs mainly include disulphide bond formation, proteolytic cleavages, glycosylation, phosphorylation, and sulphation, and many of them are highly reversible and dynamic which contributes to complex protein activity, stability and location (Yang et al., 2015). Therefore, research on posttranslational modified proteins is still a big challenge.

However, continuous technological advancements greatly facilities the research on PTMs. Highresolution mass spectrometry (MS) has become an inevitable tool to detect and quantify PTMs. A public database named Phospho Site Plus( PSP ) has described about 240000 phosphorylation and 22000 ubiquitination sites for more than 20000 proteins by MS/MS experiments( $\mathrm{Li}$ et al., 2018). Besides, dynamic range compression before hexapeptide libraries can increase the detection sensitivity of low-abundance protein and PTMs. When combined MS, dynamic range compression and hexapeptide libraries, nearly double salivary phosphoprotein and $\mathrm{N}$-glycoprotein identifications were observed. Sample enrichment and network-based proteinprotein interactions have also been demonstrated to be powerful tools identifying the full suite of PTMs with a focus on phosphorylation and glycosylations ( Schulz et al., 2013b;Amiri et al., 2018).

\section{Problems}

Reliable biomarkers are required to be not only highly disease-related, but also stable. The rigor and reproducibility of salivary proteomic biomarkers is one of the critical problems we are facing now. Firstly, salivary molecular identification and evaluation might vary from one experiment to another. A standardized system for saliva collection and analysis is therefore indispensable. In addition, salivary proteins are vulnerable to environmental factors like proteolytic enzymes, oral microorganisms, and circadian patterns(Bonne and Wong, 2012). Immediate processing, the use of freezers and protease inhibitors are recommended to tackle this problem. As we all know, many informative proteins are generally present in lower amounts in saliva than in serum (Javaid et al., 2015), so highly sensitive tools and methods are necessary for salivary proteomic analysis. Moreover, it is very necessary to combine salivary proteomic analysis with conventional oral examinations. Finally, it is definite that salivary proteomic candidates require extensive validation in large patient cohorts before they can be translated into clinical applications.
We hope that in the near future, salivary proteomic biomarkers will be specific enough to screen oral cancer at an early stage, and to improve life quality of oral cancer patients greatly.

\section{Acknowledgements}

This work was supported by the National Natural Science Foundation of China (No.81372892), the Research Foundation (SKLOD201601) from the State Key Laboratory of Oral Disease Sichuan University.

\section{References}

Agha-Hosseini, F., and Mirzaii-Dizgah, I. (2015). Serum and saliva collagenase-3 (MMP-13) in patients with oral lichen planus and oral squamous cell carcinoma. Med J Islamic Republic of Iran 29, 218-218. PMID:26478876

Al-Tarawneh, S.K., Border, M.B., Dibble, C.F., and Bencharit, S. (2011). Defining salivary biomarkers using mass spectrometry-based proteomics: a systematic review. Omics A J Integr Biol 15, 353. https://dx.doi.org/ 10.1089/omi.2010.0134

Amiri, D.A.N., Koushki, M., Rezaei, T.M., and Ahmadi, N.A. (2018). Protein-Protein Interaction Network Analysis of Salivary Proteomic Data in Oral Cancer Cases. Asian Pac J Cance 19(6), 1639. https://dx.doi.org/10.22034/APJCP. 2018.19.6.1639

Ardito, F., Perrone, D., Cocchi, R., Russo, L.L., Lillo, A.D., Giannatempo, G., and Muzio, L.L. (2016). Novel possibilities in the study of the salivary proteomic profile using SELDI-TOF/MS technology. Oncol Lett 11, 1967-1972. https:// dx.doi.org/ 10.3892/ol.2016.4219

Bandhakavi, S., Stone, M.D., Onsongo, G., Van Riper, S.K., and Griffin, T.J. (2009). A dynamic range compression and three-dimensional peptide fractionation analysis platform expands proteome coverage and the diagnostic potential of whole saliva. J Proteome Res 8, 5590-5600. https:// dx.doi.org/10.1021/pr900675w

Castagnola, M., Cabras, T., lavarone, F., Fanali, C., Nemolato, S., Peluso, G., Bosello, S.L., Faa, G., Ferraccioli, G., and Messana, I. (2012). The human salivary proteome: a critical overview of the results obtained by different proteomic platforms. Expert Rev Proteomics 9, 33-46. https://dx.doi.org/10.1586/epr.11.77

Castagnola, M., Cabras, T., lavarone, F., Vincenzoni, F., Vitali, A., Pisano, E., Nemolato, S., Scarano, E., Fiorita, A., and Vento, G. (2012b). Top-down platform for deciphering the human salivary proteome. J matern-fetal neo med 
2012,25(S5), 27-43. https://dx.doi.org/ 10.3109/14767058.2012.714647

Chaubron, F. (2015). Method of evaluating cancer risk in human (EP).

Chen, Y.T., Chen, H.W., Wu, C.F., Chu, L.J., Chiang, W.F., Wu, C.C., Yu, J.S., Tsai, C.H., Liang, K.H., and Chang, Y.S. (2017). Development of a multiplexed LC-MRM/MS method for evaluation of salivary proteins as oral cancer biomarkers. Mol Cell Proteomics. https://dx.doi.org/10.1074/ mcp.M116.064758

Cheng, Y.S.L., Rees, T., and Wright, J. (2014). A review of research on salivary biomarkers for oral cancer detection. Clin Transl Med 3, 3. https:// dx.doi.org/ 10.1186/2001-1326-3-3

Gallo, C., Ciavarella, D., Santarelli, A., Ranieri, E., Colella, G., Lo, M.L., and Lo, R.L. (2016). Potential Salivary Proteomic Markers of Oral Squamous Cell Carcinoma. Cancer Genom Proteom 13, 55. PMID: 26708599

Ghallab, N.A., and Shaker, O.G. (2016). Serum and salivary levels of chemerin and MMP-9 in oral squamous cell carcinoma and oral premalignant lesions. Clin Oral Invest 1-11. https://dx.doi.org/ 10.1007/s00784-016-1846-8.

Han, G., Wei, Z., Lu, Z., Cui, H., Bai, X., Ge, H.E., and Zhang, W. (2014). Association between matrix metalloproteinase $1-1607$ 1G>2G polymorphism and cancer risk: a meta-analysis including 19706 subjects. Int J Clin Experim Med 7, 2992. PMID: 25356173

Haywood, B., Dastane, A., and Lin, F.C. (2011). Protease inhibitor sample collection. system (EP).

Jessie, K., Jayapalan, J.J., Ong, K.C., Abdul Rahim, Z.H., Zain, R.M., Wong, K.T., and Hashim, O.H. (2013). Aberrant proteins in the saliva of patients with oral squamous cell carcinoma. Electrophoresis 34, 2495-2502. https://dx.doi.org/ 10.1002/elps.-201300107

Kaczor-Urbanowicz, K.E., Martin, C.-P.C., Aro, K., Tu, M., Garcia-Godoy, F., and Wong, D.T. (2016). Saliva diagnostics - Current views and directions. Experim Biol Med 242(5):459-472. https:// dx.doi.org/ 10.1177/1535370216681550

Kaczor-Urbanowicz, K.E., Martín, C.-P.C., Kaczor,

T., Tu, M., Wei, F., Garcia-Godoy, F., and Wong,

D.T. (2017). Emerging technologies for salivaomics in cancer detection. J Cel Mol Medi 21, 640. https://dx.doi.org/10.1111/jcmm. 13007 Kao, Y.H., and Tang, Y.C. (2014). Resistin.

Karsani, S.A., Saihen, N.A., Zain, R.B., Cheong, S.C., and Abdul, R.M. (2014). Comparative proteomics analysis of oral cancer cell lines: Identification of cancer associated proteins.
Proteom Sci 12, 3. https://dx.doi.org/ 10.1186/1477-5956-12-3

Kaur, J., Jacobs, R., Huang, Y., Salvo, N., and Politis, C. (2018). Salivary biomarkers for oral cancer and pre-cancer screening: a review. Clin Oral Invest 22, 633. https://dx.doi.org/10.1007/ s00784-018-2337-x

Kawas, S.A., Rahim, Z.H.A., and Ferguson, D.B. (2012). Potential uses of human salivary protein and peptide analysis in the diagnosis of disease. Arch Oral Biol 57, 1-9. https://dx.doi.org/10.1016/ j.archoralbio.2011.06.013

Krapfenbauer, K. (2014). Identification of tumourrelated proteins as potential screening markers by proteome analysis-protein profiles of human saliva as a predictive and prognostic tool. EPMA $\mathrm{J}$ 5, $\quad 1-15$. https://dx.doi.org/ 10.1186/1878-5085-5-20

Li, G.X.H., Vogel, C., and Choi, H. (2018). PTMscape: an open source tool to predict generic post-translational modifications and map modification crosstalk in protein domains and biological processes. Mol Omics 14, 197-209. https://dx.doi.org/-10.1039/c8mo00027a

Liang, Q., Liu, H., Li, X., and Zhang, A.H. (2016). High-throughput metabolomics analysis discovers. salivary biomarkers for predicting mild cognitive impairment and Alzheimer's disease. Rsc Advances. https://dx.doi.org/10.1039/ C6RA16802G

Loo, J.A., Yan, W., Ramachandran, P., and Wong, D.T. (2010). Comparative Human Salivary and Plasma Proteomes. J Dent Res 89, 1016-1023. https://-dx.doi.org/10.1177/0022034510380414

Malathi, N., Mythili, S., and Vasanthi, H.R. (2014). Salivary diagnostics: a brief review. Isrn Dent 2014, 158786 . https://dx.doi.org/ $10.1155 / 2014 / 158786$

Martelli, C., lavarone, F., Vincenzoni, F., Rossetti, D.V., D'Angelo, L., Tamburrini, G., Caldarelli, M., Di, R.C., Messana, I., and Castagnola, M. (2014). Proteomic characterization of pediatric craniopharyngioma intracystic fluid by LC-MS topdown/bottom-up integrated approaches. Electrophoresis 35, 2172-2183. https://dx.doi.org/ 10.1002/elps.201300578

Marx, J. Inflammation and cancer: the link grows stronger. Science. https://-dx.doi.org/10.1126/ science.306.5698.966

Metgud, R., and Patel, S. (2014). Serum and salivary levels of albumin as diagnostic tools for oral pre-malignancy and oral malignancy. Biotech Histochem 89, 8-13. http://dx.doi.org/ 10.3109/10520295.2013.793394 
Mu, A.K., Chan, Y.S., Kang, S.S., Azman, S.N., Zain, R.B., Chai, W.L., and Chen, Y. (2014). Detection of host-specific immunogenic proteins in the saliva of patients with oral squamous cell carcinoma. J Immun and Immunochem 35, 183-193.https://dx.doi.org/10.1080/15321819.2013.836535

Nunes, L.A.S., Brenzikofer, R., and Macedo, D.V. (2011). Reference intervals for saliva. analytes collected by a standardized method in a physically active population. Clin Biochem 44, 1440-1444. https://dx.doi.org/10.1016/j.clinbiochem. 2011.09.012

Nunes, L.A.S., Mussavira, S., and Bindhu, O.S. (2015a). Clinical and diagnostic utility of saliva as a non-invasive diagnostic fluid:

a systematic review. Biochemia Medica 25, 177-192. https://dx.doi.org/10.11613/BM.2015.018

Pandey, A., and Mann, M. (2000). Proteomics to study genes and genomes. Nature 405, 837-846. https://dx.doi.org/10.1038/35015709

Panta, P., and Wong, D.T.W. (2019). Salivary Biomarkers in Oral Cancer.

Pereira, A.C., Dias, d.C.E., Ma, D.D.S., and Blumer Rosa, L.E. (2012). Matrix metalloproteinase gene polymorphisms and oral cancer. J Clin Experimt Dent 4, e297-e301. https://dx.doi.org/10.4317/ jced.50859

Perezcornejo, P., Gokhale, A., Duran, C., Cui, Y., Xiao, Q., Hartzell, H.C., and Faundez, V. (2012). Anoctamin 1 (Tmem16A) Ca2+-activated chloride channel stoichiometrically interacts with an ezrinradixin-moesin network. Proc Natl Acad Sci U S A 109(26):10376-10381. https://dx.doi.org/10.4161/ cl.22717

Rabilloud, T. (2015). Two-dimensional gel electrophoresis in proteomics: old fashioned, but it still climbs up the mountains. Proteomics 2, 3-10. https://dx.doi.org/ 10.1002/1615-9861(200201) 2:13.0.CO;2-R

Sannam, K.R., Khurshid, Z., Akhbar, S., and Faraz, M.S. (2016). Advances of Salivary Proteomics in Oral Squamous Cell Carcinoma (OSCC) Detection: An Update. Proteomes 4. https:// dx.doi.org/10.3390/proteomes4040041

Santucci, L., Bruschi, M., Ghiggeri, G.M., and Candiano, G. (2015). The Latest Advancements in Proteomic Two-dimensional Gel Electrophoresis Analysis Applied to Biological Samples. Method Mol Biol 1243:103. https://dx.doi.org/ 10.1007/978-1-4939-1872-0_6

Schulz, B.L., Cooper-White, J., and Punyadeera, C.K. (2013a). Saliva proteome research: current status. and future outlook. Crit Rev Biotechnol 33, $246-259$. https://dx.doi.org/ $10.3109 / 07388551.2012 .687361$
Siegel, R.L., Miller, K.D., and PhD, A.J.D. (2018). Cancer statistics, 2018. Ca A Cancer. J Clin.

Sivadasan, P., Kumar, G.M., Sathe, G.J., Balakrishnan, L., Palit, P., Gowda, H., Suresh, A., Abraham, K.M., and Sirdeshmukh, R. (2015). Data from human salivary proteome - A resource of potential biomarkers for oral cancer. Data in Brief 4, 374-378. https://dx.doi.org/10.1016/j.dib. 2015.06.014

Sun, Y.C., Song, W., Du, N.N., Yi, S., and Wei, X. (2018). High-throughput metabolomics enables metabolite biomarkers and metabolic mechanism discovery of fish in response to alkalinity stress. Rsc Advances 8, 14983-14990. https://dx.doi.org/ $10.1039 / \mathrm{c} 8 \mathrm{ra01317a}$

Van, d.W.I. (2013). Are we able to reduce the mortality and morbidity of oral cancer: some considerations. Med Oral Patol Oral Cir Bucal 18, 33-37.https://dx.doi.org-/10.4317/medoral.18486

Wong, D.T. (2012). Salivaomics. J Amer Dent Associat 143,19S-24S. https://-dx.doi.org/ 10.14219/jada.archive.2012.0339

Wu, C.C., Chu, H.W., Hsu, C.W., Chang, K.P., and Liu, H.P. (2015). Saliva proteome profiling reveals potential salivary biomarkers for detection of oral cavity squamous cell carcinoma. Proteomics 15 , 3394-3404. https://dx.doi.org/10.1002/ pmic.-201500157

Yang, Y.S., Wang, C.C., Chen, B.H., Hou, Y.H., Hung, K.S., and Mao, Y.C. (2015). Tyrosine Sulfation as a Protein Post-Translational Modification. Molecules 20, 2138. https:// dx.doi.org/10.3390/molecules20022138

Yu, J.S., Chen, Y.T., Chiang, W.F., Hsiao, Y.C., Chu, L.J., See, L.C., Wu, C.S., Tu, H.T., Chen, H.W., and Chen, C.C. (2016). Saliva protein biomarkers to detect oral squamous cell carcinoma in a highrisk population in Taiwan. Pe National Acad Sci USA 113, 11549. https://dx.doi.org/10.1073/pnas. 1612368113

Zhang, A., Sun, H., Wang, P., and Wang, X. (2013). Salivary proteomics in biomedical research. Clinica Chimica Acta 415, 261-265. https:// dx.doi.org/10.1016/j.cca.-2012.11.001

Bonne, N.J., and Wong, D.T. (2012). Salivary biomarker development using genomic, proteomic and metabolomic approaches. Genome Med 4(10), 82. https://dx.doi.org/ 10.1186/gm383

Javaid, M.A., Ahmed, A.S., Durand, R., and Tran, S.D. (2015). Saliva as a diagnostic tool for oral and systemic diseases. J Oral Biol and Craniofac Res 6, 67-76. https://dx.doi.org/10.1016/j.jobcr. 2015.08.006 
